OPEN

SUBJECT AREAS:

ENVIRONMENTAL

CHEMISTRY

MAGNETIC MATERIALS

CATALYST SYNTHESIS

SUSTAINABILITY

Received

18 April 2013

Accepted

16 July 2013

Published

13 August 2013

Correspondence and requests for materials should be addressed to H.J. (jhong@ustc.edu.

\title{
Facile synthesis of highly efficient and recyclable magnetic solid acid from biomass waste
}

\author{
Wu-Jun Liu, Ke Tian, Hong Jiang \& Han-Qing Yu
}

Department of Chemistry, University of Science and Technology of China, Hefei 230026, China.

In this work, sawdust, a biomass waste, is converted into a magnetic porous carbonaceous (MPC) solid acid catalyst by an integrated fast pyrolysis-sulfonation process. The resultant magnetic solid acid has a porous structure with high surface area of $296.4 \mathrm{~m}^{2} \mathrm{~g}^{-1}$, which can be attributed to the catalytic effect of Fe. The catalytic activity and recyclability of the solid acid catalyst are evaluated during three typical acid-catalyzed reactions: esterification, dehydration, and hydrolysis. The favorable catalytic performance in all three reactions is attributed to the acid's high strength with $2.57 \mathrm{mmol} \mathrm{g}^{-1}$ of total acid sites. Moreover, the solid acid can be reused five times without a noticeable decrease in catalytic activity, indicating the stability of the porous carbon (PC)-sulfonic acid group structure. The findings in the present work offer effective alternatives for environmentally friendly utilization of abundant biomass waste.

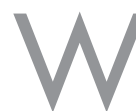

ith the depletion of fossil fuels, development of renewable energy has attracted an increasing amount of interest. Acidic materials are widely used in the catalytic production of a variety of renewable fuels (e.g., biodiesels) and fine chemicals (e.g., furfurals and sugars) ${ }^{1-3}$. In the past, liquid mineral acids (e.g., $\mathrm{HCl}$, $\mathrm{H}_{2} \mathrm{SO}_{4}$, and $\mathrm{H}_{3} \mathrm{PO}_{4}$ ) have been widely used to catalyze these reactions ${ }^{1,4}$. However, many disadvantages, such as strong corrosiveness, costly and inefficient separation from homogeneous reaction mixtures, and creation of a large amount of waste by-products, have limited the applications of liquid mineral acids in many fields ${ }^{5}$. Alternatively, solid acids including solid Brønsted acids (e.g., $\mathrm{SO}_{3} \mathrm{H}$ functionalized carbon and polymers) ${ }^{6-9}$ in addition to solid Lewis acids (transition-metal (W, $\mathrm{Zr}, \mathrm{Nb}$ ) oxides) $)^{10,11}$ are easily separated from the reaction mixture and can be reused. Thus, solid acids have been used to replace liquid mineral acids in catalytic reactions such as esterification, dehydration, and hydrolysis during biofuel production to minimize adverse effects on the environment and to reduce expenses ${ }^{5,12-16}$. Porous carbonaceous (PC) solid acids are widely used catalysts in acidcatalyzed reactions. Nakajima et al. ${ }^{6}$ reported that these acids can be synthesized by sulfonation of partially carbonized organic matter including sugars, cellulosic materials, and synthetic polymers and can be used in many acid catalytic reacions such as hydrolysis of $\beta-1,4$ glucan and biodiesel production. Arancon et al. ${ }^{17}$ synthesized a PC solid acid from corncob residue, which demonstrated favorable catalytic performance in the esterification/transesterification of waste oils. Wu et al. ${ }^{18}$ prepared sulfonated bio-char as a solid acid for the hydrolysis of crystalline cellulose.

Compared with conventional solid acids, magnetic solid acids can be separated more easily in the presence of external magnetic fields, particularly in viscous or solid reaction mixtures ${ }^{19,20}$. The most common method used for synthesis of magnetic solid acid catalysts is sulfonation of a mesoporous structure with a magnetic core, generally $\mathrm{Fe}_{3} \mathrm{O}_{4}$. In a previous study, a magnetic solid acid with a high acid strength of $2.2-2.5 \mathrm{H}^{+} / \mathrm{mol}$ was prepared through sulfonation of polystyrene-encapsulated $\mathrm{Fe}_{3} \mathrm{O}_{4}$ spheres ${ }^{21}$. More recently, a series of magnetic nano-sized solid acid catalysts was synthesized by sulfonation of a series of particles containing $\mathrm{Fe}_{3} \mathrm{O}_{4}$ cores with various shell materials (e.g., polystyrene, poly(glycidyl methacrylate), and silica) ${ }^{22}$. All of these catalysts exhibit high activity and excellent separability in the acid-catalyzed reactions. However, many magnetic solid acid catalysts reported thus far have been determined as unsatisfactory for acid catalyzed reactions. For example, $\mathrm{SO}_{3} \mathrm{H}$-functionalized polymers often exhibit low thermal stability and are costly ${ }^{23}$. In addition, the preparation of these magnetic solid acid catalysts involves complex synthetic procedures and often requires expensive reagents, which impedes largescale production and commercialization.

In our continuing efforts toward biomass waste disposal and resource recovery ${ }^{24-27}$, we have developed a rapid, low-cost, and readily scalable approach for synthesizing a magnetic porous carbonaceous solid acid catalyst $\left(\mathrm{MPC}-\mathrm{SO}_{3} \mathrm{H}\right)$ by using biomass waste as a precursor. This method involves fast pyrolysis of Fe-preloaded 
biomass to produce MPC material; subsequent sulfonation of the obtained material is used to prepare a solid acid catalyst. This process also produces bio-oil, a renewable liquid that can be used for fuel and chemical production ${ }^{28-30}$.

\section{Results}

A schematic illustration of the synthetic pathway for $\mathrm{MPC}-\mathrm{SO}_{3} \mathrm{H}$ is shown in Fig. 1. Synthesis of MPC precursor materials is the primary step for $\mathrm{MPC}-\mathrm{SO}_{3} \mathrm{H}$ synthesis, which includes the following steps: The Fe preloaded on the biomass in the form of $\mathrm{FeCl}_{3}$ is hydrolyzed to Fe hydroxides $(\mathrm{FeO}(\mathrm{OH}))$ in the drying process (Eqs. 1, 2). The Fepreloaded biomass is then subjected to a pyrolysis process to be converted into MPC material. In this process, the Fe-preloaded biomass is thermally decomposed, and the produced volatile components are swept out by the carrier gas $\left(\mathrm{N}_{2}\right)$ and condensed to produce bio-oil. The $\mathrm{FeO}(\mathrm{OH})$ is reduced to $\mathrm{Fe}_{3} \mathrm{O}_{4}$ under mesothermal conditions at $673-873 \mathrm{~K}$ by reducing components including $\mathrm{H}_{2}, \mathrm{CO}$, and amorphous carbon, which were formed during the pyrolysis

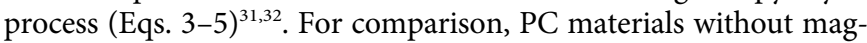
netism that were derived from raw biomass are also synthesized.

$$
\begin{gathered}
\mathrm{FeCl}_{3}+3 \mathrm{H}_{2} \mathrm{O} \rightarrow \mathrm{Fe}(\mathrm{OH})_{3}+3 \mathrm{HCl} \uparrow \\
\mathrm{Fe}(\mathrm{OH})_{3} \rightarrow \mathrm{FeO}(\mathrm{OH})+\mathrm{H}_{2} \mathrm{O} \\
6 \mathrm{FeO}(\mathrm{OH})+4 \mathrm{H}_{2} \rightarrow 2 \mathrm{Fe}_{3} \mathrm{O}_{4}+4 \mathrm{H}_{2} \mathrm{O} \uparrow \\
6 \mathrm{FeO}(\mathrm{OH})+4 \mathrm{C} \rightarrow 2 \mathrm{Fe}_{3} \mathrm{O}_{4}+2 \mathrm{CO} \uparrow \\
6 \mathrm{FeO}(\mathrm{OH})+4 \mathrm{CO} \rightarrow 2 \mathrm{Fe}_{3} \mathrm{O}_{4}+4 \mathrm{CO}_{2} \uparrow
\end{gathered}
$$

Figure 2a shows X-ray diffraction (XRD) patterns of MPC (Pattern A) and PC (Pattern B). Both patterns show a weak but broad diffraction peak of $2 \theta$ at $\sim 23^{\circ}$, which can be attributed to the amorphous carbon composed of aromatic carbon sheets oriented in a relatively random manner ${ }^{33}$. The XRD peaks in Pattern A of $2 \theta$ at $30.1^{\circ}, 35.7^{\circ}$, $37.1^{\circ}, 43.2^{\circ}, 53.6^{\circ}, 62.7^{\circ}$, and $74.9^{\circ}$ indicate the formation of $\mathrm{Fe}_{3} \mathrm{O}_{4}$ crystallite in the fast pyrolysis process according to Joint Committee on Powder Diffraction Standard (JCPDS) 19-0629. Figure 2b shows the nitrogen sorption isotherms of MPC and PC. For Pattern A, the isotherms exhibit a typical type III pattern with an $\mathrm{H} 2$-type hysteresis loop at high relative pressures, indicating that the pores of MPC have uniform sizes and shapes ${ }^{34}$. For Pattern B, however, the isotherms exhibit a typical type II pattern without a significant hysteresis loop, suggesting that PC is nearly devoid of pores. Based on the nitrogen quantity adsorbed at different relative pressures, the surface area of the MPC is calculated by the Brunauer-Emmett-Teller (BET) method to be $391.7 \mathrm{~m}^{2} \mathrm{~g}^{-1}$, which is significantly higher than that of PC at $14.0 \mathrm{~m}^{2} \mathrm{~g}^{-1}$. This result indicates that the presence of Fe can catalyze the formation of porous structures during biomass carbonization mainly because the dehydration and decomposition of $\mathrm{FeCl}_{3}$ can enhance the release of volatile matter such as $\mathrm{HCl}, \mathrm{H}_{2} \mathrm{O}, \mathrm{CO}$, and $\mathrm{CO}_{2}$ (Eqs. 1-5) during the biomass pyrolysis process, which generally produces an increase in surface area and pore volume. Similar phenomena have been observed in the carbonization of $\mathrm{FeCl}_{3}$-impregnated pinewood sawdust and carbon aerogels containing $\mathrm{Fe}^{35,36}$. $\mathrm{FeCl}_{3}$ easily dehydrates carbohydrate polymers (e.g., cellulose and hemicellulose) at high temperatures and can change the decomposition pathway of lignocellulosic biomass during fast pyrolysis to inhibit the formation of heavy tars that may block pore structures, thus improving the formation of open pores in the carbon matrix. Furthermore, the formed Fe species, e.g., $\mathrm{FeOOH}$ or $\mathrm{Fe}_{3} \mathrm{O}_{4}$ may act as an in situ catalyst in the fast pyrolysis process for the generation of porous structures ${ }^{37}$.

Scanning electron microscopy (SEM) and transmission electron microscopy (TEM) show a very rough MPC surface morphology (Fig. 2c). Energy dispersive X-ray (EDX) results indicate that the surface is composed mainly of $\mathrm{C}, \mathrm{O}$, and Fe elements (Fig. 2d) and many wire-like structures, which are also confirmed by TEM (Fig. 2e). In addition, porous structures are also observed in the TEM image. Conversely, neither wire-like nor porous structures are detected in the SEM and TEM images for PC (Figs. $2 \mathrm{f}$ and $2 \mathrm{~g}$ ). These results confirm those of the nitrogen sorption isotherms, which indicate that MPC has porous structures with high surface area, and PC has very low surface area and is nearly devoid of porous structures.

A sulfonation process is applied to both MPC and PC to produce $\mathrm{MPC}-\mathrm{SO}_{3} \mathrm{H}$ and $\mathrm{PC}-\mathrm{SO}_{3} \mathrm{H}$. Figure $3 \mathrm{a}$ shows the XRD pattern of

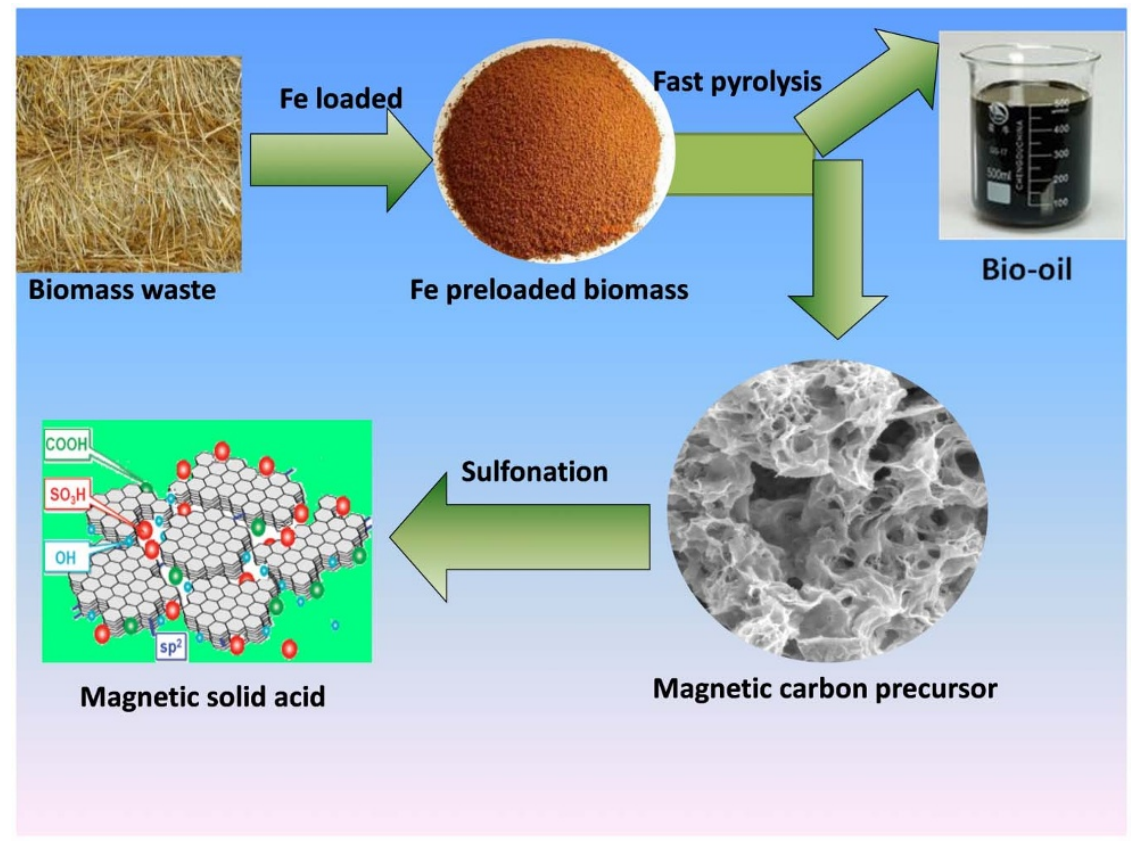

Figure 1 Schematic illustration of the synthesis of a magnetic porous carbonaceous (MPC) solid acid catalyst from naturally abundant biomass waste (all photographs and images were produced by W. J. Liu). 


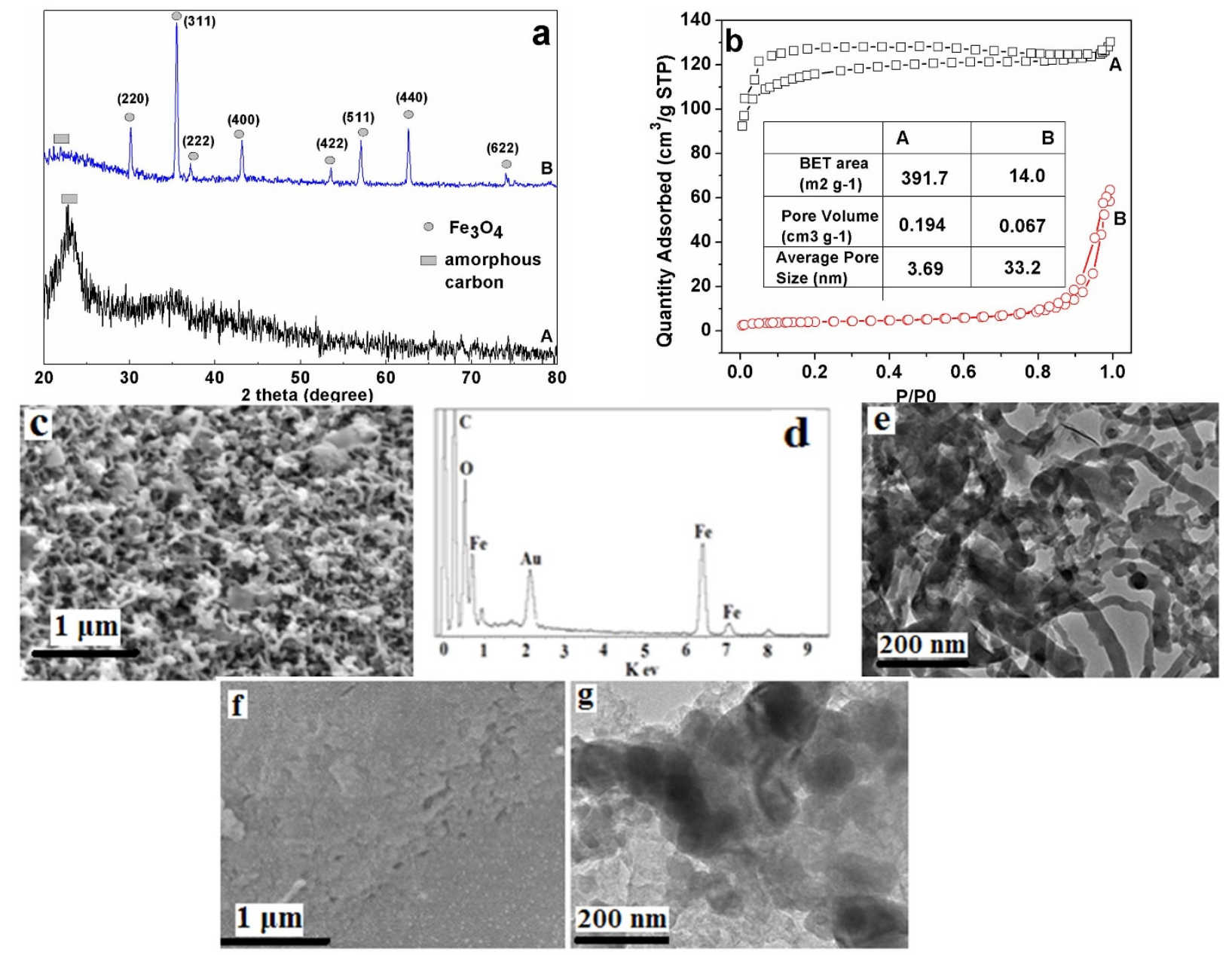

Figure 2 (a) X-ray diffraction (XRD) patterns of the magnetic porous carbonaceous (MPC) solid acid precursor (pattern A) and the precursor of the carbonaceous solid acid without magnetism (PC) (pattern B). (b) $\mathrm{N}_{2}$ adsorption-desorption isotherms of MPC and PC. (c) Scanning electron microscopy (SEM) image of MPC. (d) Energy dispersive X-ray (EDX) analysis of MPC; the Au is a film applied before SEM analysis to improve conductivity of MPC. (e) Transmission electron microscopy (TEM) image of MPC. (f) SEM image of PC. (g) TEM image of PC.

MPC- $\mathrm{SO}_{3} \mathrm{H}$, which indicates that $\mathrm{Fe}_{3} \mathrm{O}_{4}$ remains after sulfonation. The density and distribution of the $\mathrm{S}$ and Fe elements in $\mathrm{MPC}-\mathrm{SO}_{3} \mathrm{H}$ are evaluated by quantitative EDX mapping. $\mathrm{S}$ is determined to be homogeneously distributed on the entire surface of $\mathrm{MPC}-\mathrm{SO}_{3} \mathrm{H}$ (Fig. 3e), suggesting effective sulfonation of the carbonaceous precursor material. As shown in Fig. 3f, Fe is also homogeneously distributed on the entire surface of $\mathrm{MPC}-\mathrm{SO}_{3} \mathrm{H}$ after sulfonation, which is consistent with the XRD results such that the $\mathrm{Fe}_{3} \mathrm{O}_{4}$ structure is not damaged in the sulfonation reaction and thus the magnetism of the solid acid catalyst remains. The results of analysis of surface area and pore volume of MPC- $\mathrm{SO}_{3} \mathrm{H}$ and $\mathrm{PC}-\mathrm{SO}_{3} \mathrm{H}$ by nitrogen adsorptiondesorption isotherms are shown in Fig. 3b, Fig. S1, and Table S1. The surface area and pore volume of MPC- $\mathrm{SO}_{3} \mathrm{H}$ are $296.4 \mathrm{~m}^{2} \mathrm{~g}^{-1}$ and $0.14 \mathrm{~cm}^{-3} \mathrm{~g}^{-1}$, respectively, which are slightly lower than those of MPC. This result suggests that pore structure of MPC has been partially damaged in the sulfonation process. However, as shown in the SEM and TEM images (Figs. 3c and 3d), the wire-like and porous structures of MPC are nearly unchanged after the sulfonation process.

The surface composition of $\mathrm{MPC}-\mathrm{SO}_{3} \mathrm{H}$ is analyzed by X-ray photoelectron spectroscopy (XPS). The $\mathrm{C} 1 \mathrm{~s}$ spectrum includes six peaks with differentiated binding energy values via deconvolution (Fig. $3 \mathrm{~g}$ ). These peaks could be assigned to the carbon atoms in the forms of C-S (284.1 eV), C-C (284.6 and $284.9 \mathrm{eV}), \mathrm{C}-\mathrm{O}$ (alcoholic, phenolic hydroxyl and/or ether, $285.4 \mathrm{eV}), \mathrm{C}=\mathrm{O}$ (carbonyl and/or quinine, $286.7 \mathrm{eV}$ ), and $\mathrm{O}=\mathrm{C}-\mathrm{O}$ (carboxyl groups, $289.0 \mathrm{eV})^{38,39}$. For comparison, the $\mathrm{C} 1 \mathrm{~s}$ spectrum of MPC prior to sulfonation is shown in Fig. S2, in which only two carbon forms, C-C and C-O, are apparent. This result indicates that the sulfonation process not only introduces $\mathrm{SO}_{3} \mathrm{H}$ groups on the carbon matrix through the formation of $\mathrm{C}-\mathrm{S}$ bonds but also modifies the surface of the materials with additional oxygenated functional groups (e.g., $\mathrm{C}=\mathrm{O}$ and $\mathrm{O}-\mathrm{C}=$ $\mathrm{O})$. The $\mathrm{S} 2 \mathrm{p}$ spectrum of $\mathrm{MPC}-\mathrm{SO}_{3} \mathrm{H}$ shows three different peaks (Fig. 3h), which could be attributed to the S-C (168.1 eV), S-O $(168.9 \mathrm{eV})$, and $\mathrm{S}=\mathrm{O}$ bonds $(169.9 \mathrm{eV})^{6,40}$. These three bonds further indicate that the $\mathrm{S}$ in MPC- $\mathrm{SO}_{3} \mathrm{H}$ is mainly in the form of $\mathrm{SO}_{3} \mathrm{H}$ groups bonded to carbon matrix ${ }^{41}$.

Because the XPS results indicate that the $\mathrm{S}$ in $\mathrm{MPC}-\mathrm{SO} 3 \mathrm{H}$ is mainly associated with $\mathrm{SO}_{3} \mathrm{H}$ groups, the $\mathrm{SO}_{3} \mathrm{H}$ contents of MPC$\mathrm{SO}_{3} \mathrm{H}$ can be estimated from the $\mathrm{S}$ content. The $\mathrm{S}$ content of MPC$\mathrm{SO}_{3} \mathrm{H}$ and $\mathrm{PC}-\mathrm{SO}_{3} \mathrm{H}$ is $5.6 \mathrm{wt} . \%$ and $3.1 \mathrm{wt} . \%$, respectively (Table $\mathrm{S} 2$ ). Thus, the $\mathrm{SO}_{3} \mathrm{H}$ contents of $\mathrm{MPC}-\mathrm{SO}_{3} \mathrm{H}$ and $\mathrm{PC}-\mathrm{SO}_{3} \mathrm{H}$ are calculated to be $1.75 \mathrm{mmol} \mathrm{g}^{-1}$ and $0.97 \mathrm{mmol} \mathrm{g}^{-1}$, respectively. The total acid sites of $\mathrm{MPC}-\mathrm{SO}_{3} \mathrm{H}$ and $\mathrm{PC}-\mathrm{SO}_{3} \mathrm{H}$ are $2.57 \mathrm{mmol}$ $\mathrm{g}^{-1}$ and $1.26 \mathrm{mmol} \mathrm{g}^{-1}$, respectively, as determined through titration of a $\mathrm{NaOH}$ solution. The larger contents of the acid sites compared with those of $\mathrm{SO}_{3} \mathrm{H}$ in the solid acid suggest that acidic groups other than $\mathrm{SO}_{3} \mathrm{H}$ groups, such as $\mathrm{COOH}$, are also present in the solid $\operatorname{acid}^{18,42}$. This theory is confirmed through XPS and Fourier transform infrared spectroscopy (FTIR) (Fig. S3). 

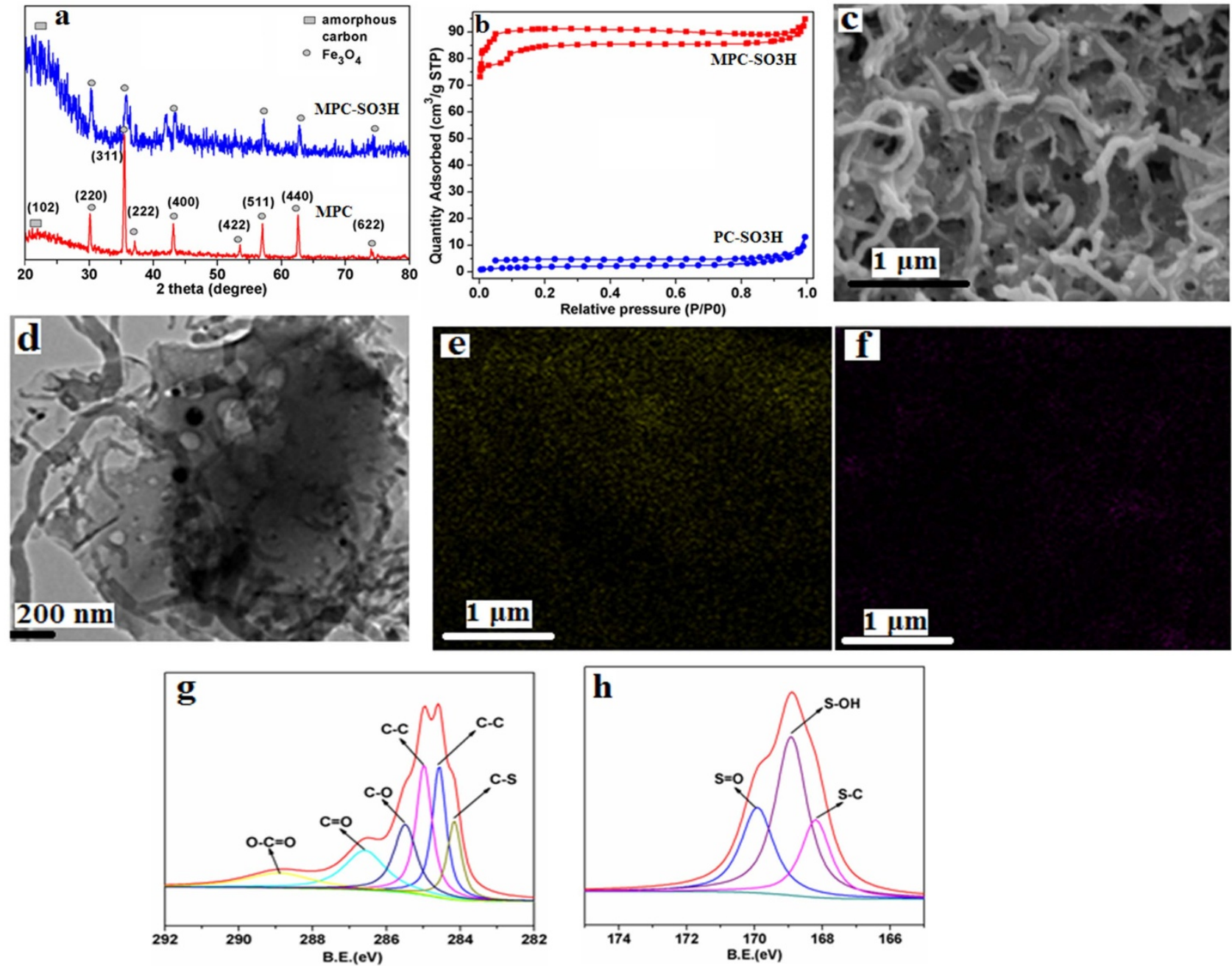

Figure 3 (a) X-ray diffraction (XRD) patterns of magnetic porous carbonaceous solid acid ( $\left.\mathrm{MPC}-\mathrm{SO}_{3} \mathrm{H}\right)$. (b) $\mathrm{N}_{2}$ adsorption-desorption isotherms of MPC- $\mathrm{SO}_{3} \mathrm{H}$ and porous carbonaceous solid acid $\left(\mathrm{PC}-\mathrm{SO}_{3} \mathrm{H}\right)$. (c) Scanning electron microscopy (SEM) image of MPC-SO $\mathrm{S}_{3} \mathrm{H}$. (d) Transmission electron microscopy (TEM) image of MPC. (e) Distribution of S in $\mathrm{MCP}_{-} \mathrm{SO}_{3} \mathrm{H}$. (f) Distribution of Fe in $\mathrm{MCP}^{-S \mathrm{O}_{3} \mathrm{H}}$. (g) C 1s X-ray photoelectron spectroscopy (XPS) spectrum of MPC- $\mathrm{SO}_{3} \mathrm{H}$. (h) S 2p XPS spectrum of MPC-SO $\mathrm{S}_{3} \mathrm{H}$.

The catalytic activities of the solid acids are evaluated in three typical acid-catalyzed reactions (Fig. 4). For Reaction A, MPC$\mathrm{SO}_{3} \mathrm{H}$ exhibits high activity for the catalytic formation of benzyl acetate with a yield of $93 \%$, which is significantly higher than that of $\mathrm{PC}-\mathrm{SO}_{3} \mathrm{H}$ at $63 \%$ and comparable to that of concentrated sulfuric acid at $89 \%$ (Fig. $5 \mathrm{a}$ ). For Reaction B, one of the primary reactions for the production of furfural from renewable biomass, only $35 \%$ of the xylose is converted in the absence of a catalyst, and no furfural is produced (Fig. 5 b). The furfural yields of $45 \%, 61 \%$, and $65 \%$ with the catalysis of $\mathrm{PC}-\mathrm{SO}_{3} \mathrm{H}, \mathrm{MPC}-\mathrm{SO}_{3} \mathrm{H}$, and commercially available $\mathrm{H}_{2} \mathrm{SO}_{4}$, respectively, indicate a favorable catalytic performance of the magnetic solid acid ${ }^{43,44}$. Moreover, as shown in Fig. S4, more than $96 \%$ of the xylose can be converted within $6 \mathrm{~h}$ with the catalysis of $\mathrm{MPC}-\mathrm{SO}_{3} \mathrm{H}$. For Reaction C, no sucrose is hydrolyzed in the absence of a catalyst (Fig. 5c); however, a hydrolysis conversion of $89 \%$ with the catalysis of $\mathrm{PC}-\mathrm{SO}_{3} \mathrm{H}$ is noted with a glucose and fructose yield of $83 \%$. These results are significantly lower than those of $\mathrm{MPC}-\mathrm{SO}_{3} \mathrm{H}$ and $\mathrm{H}_{2} \mathrm{SO}_{4}$, in which the hydrolysis conversions are both near $100 \%$ with monosaccharide yields of $94 \%$ and $97 \%$, respectively. Furthermore, $\mathrm{MPC}-\mathrm{SO}_{3} \mathrm{H}$ catalyzed hydrolysis of the sucrose occurs rapidly because more than $90 \%$ of the sucrose can be hydrolyzed in the first hour (Fig. S5).

For the solid acid catalyst, one of the most important advantages over the liquid mineral acid in the acid-catalyzed reaction is that it can be separated and reused easily. In the present study, the spent solid acid catalyst is separated from the reaction mixture by using a magnet (Fig. S6a) and is reused in the same esterification reaction. After five reuses, the catalytic activity of $\mathrm{MPC}-\mathrm{SO}_{3} \mathrm{H}$ remains unchanged with an average benzyl acetate yield of $\sim 90 \%$ (Fig. $5 \mathrm{~d}$ ). Moreover, the magnetism of $\mathrm{MPC}-\mathrm{SO}_{3} \mathrm{H}$ also remains after five reuses (Fig. S6b). SEM image (Fig. S7) of $\mathrm{MPC}-\mathrm{SO}_{3} \mathrm{H}$ after five repeated experiments shows no significant difference in surface morphology compared to that of the raw catalyst (Fig. 3a). The XPS results of the reused MPC- $\mathrm{SO}_{3} \mathrm{H}$ (Table S3 and Fig. S8) show no noticeable change in surface element compositions of $\mathrm{C}, \mathrm{O}, \mathrm{S}$, and $\mathrm{Fe}$, which indicates high stability of $\mathrm{MPC}-\mathrm{SO}_{3} \mathrm{H}$ in the acid-catalytic reaction. In addition, $\mathrm{MPC}-\mathrm{SO}_{3} \mathrm{H}$ also exhibits high thermal stability (Fig. S9).

\section{Discussion}

MP solid acid was synthesized through an integrated fast pyrolysissulfonation process. This process minimizes the environmental impact of large-scale production because it uses naturally abundant, renewable biomass waste as feedstock. The full advantage of such a process can be achieved if the loading of Fe can be achieved by using the biomass as a sorbent for extraction of Fe in wastewater. Bio-oil, a renewable fuel resource, was also produced during the fast pyrolysis process, which may result in additional economic benefits. 


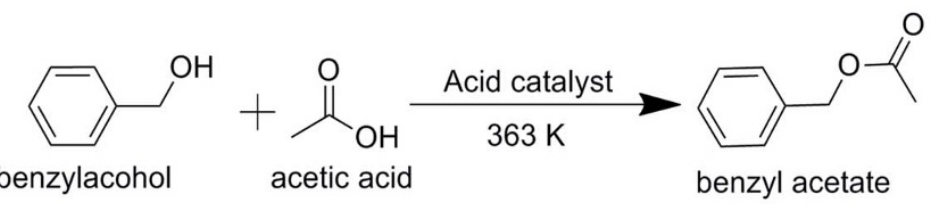

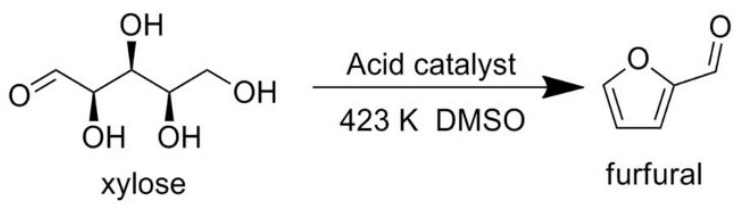<smiles>OCC1OC(O[C@@]2(CO)O[C@H](CO)[C@@H](O)[C@H]2O)[C@H](O)[C@@H](O)[C@@H]1O</smiles>

Sucrose

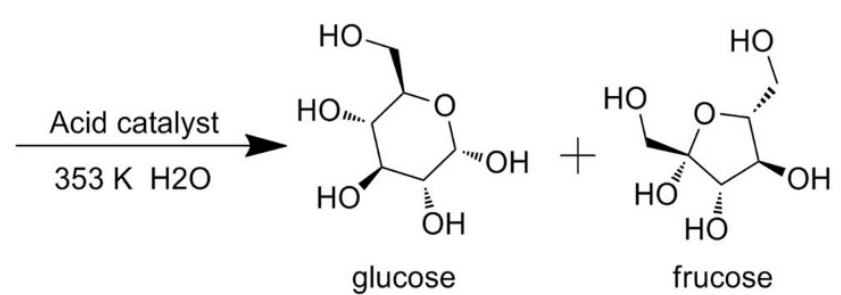

glucose

frucose

Figure $4 \mid$ The three typical acid-catalyzed reactions, esterification of benzyl alcohol and acetic acid (Reaction A), dehydration of xylose to produce furfural (Reaction B), and hydrolysis of sucrose (Reaction C).

Magnetic solid acids exhibit strong acid strength and are readily separable. Therefore, they provide promising substitutions for liquid acids in some acid catalyzed reactions, which can minimize adverse effects on the environment and human health. Furthermore, because the solid acid catalyst here is easily separated and shows high catalytic activity in reuse, it offers promising applications as a low cost, environmentally friendly, and recyclable acid catalyst in the production of fine chemicals.

In summary, we have synthesized a porous magnetic solid acid catalyst through a facile integrated fast pyrolysis-sulfonation process by using naturally abundant biomass waste. During this process, the biomass waste is first used as a sorbent to adsorb Fe(III) ions from water to obtain $\mathrm{Fe}$-loaded biomass, which is then used as pyrolysis feedstock for energy and resource recovery by creating bio-oil. The pyrolysis bio-char is then subjected to a sulfonation process to synthesize the MPC solid acid catalyst. It has been determined that the loaded $\mathrm{Fe}(\mathrm{III})$ on the biomass can be converted into $\mathrm{Fe}_{3} \mathrm{O}_{4}$ during the fast pyrolysis process, endowing the materials with magnetism that remains after the sulfonation process. In addition, the loaded $\mathrm{Fe}$ can improve formation of the porous structure on carbonaceous materials. The magnetic solid acid has a porous structure with a high surface area of $296.4 \mathrm{~m}^{2} \mathrm{~g}^{-1}$ and high acid strength with total acid sites of
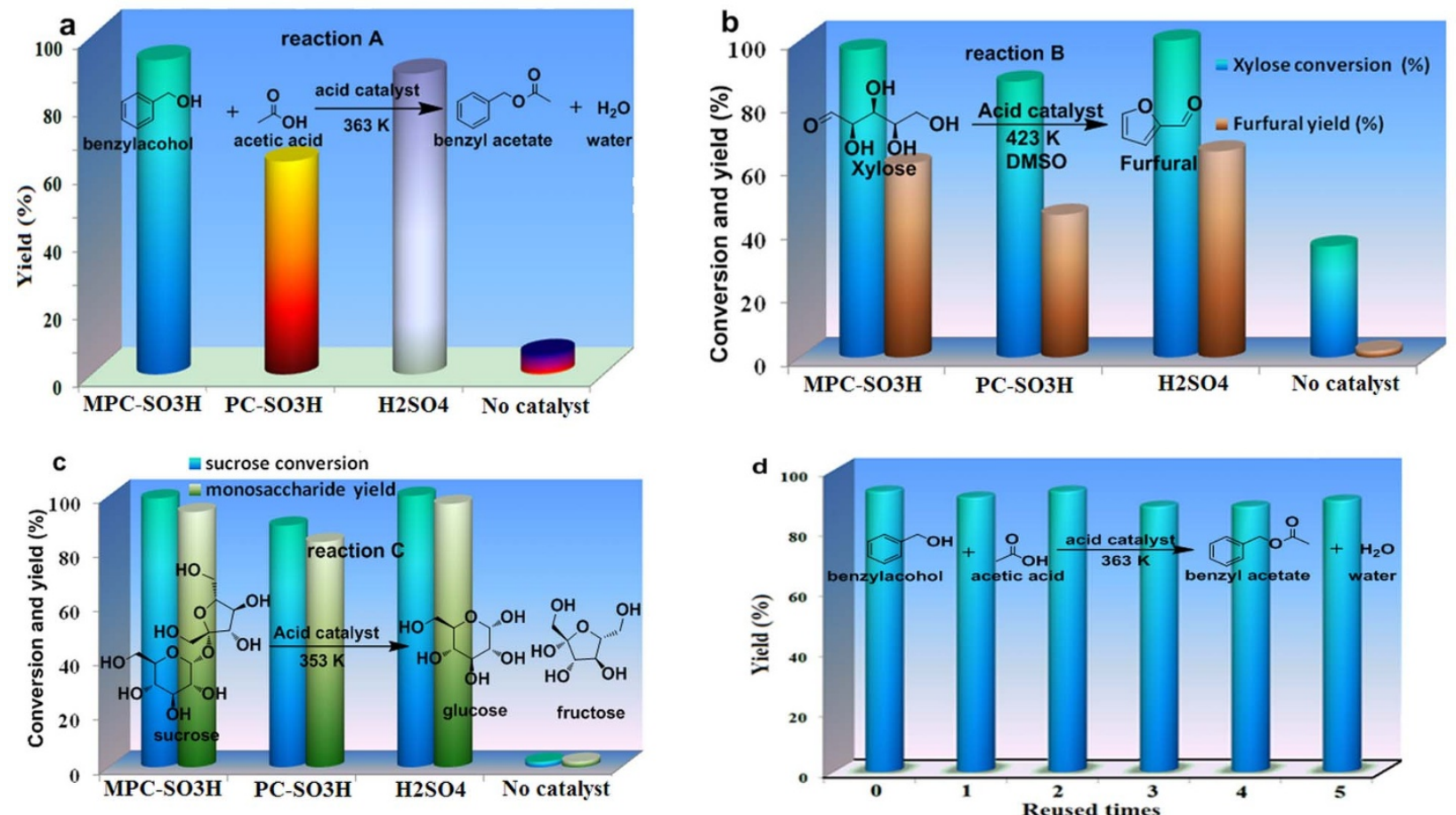

Figure $5 \mid$ (a) Comparison of the catalytic performance of $\mathrm{MPC}-\mathrm{SO}_{3} \mathrm{H}$ with other acid catalysts in the esterification of acetic acid and benzyl alcohol in (b) the dehydration of the xylose, (c) the hydrolysis of sucrose, and (d) the reuse test of catalytic activity. 
$2.57 \mathrm{mmol} \mathrm{g}^{-1}$. Moreover, this acid exhibits excellent catalytic performance, favorable separability, and high durability in typical acidcatalyzed reactions. The results presented in this work offer new opportunities for the development of facile and environmentally friendly methods of synthesizing functional materials from naturally abundant biomass waste.

\section{Methods}

Materials. All reagents and solvents were purchased from Sinopharm Chemical Reagent Co., Shanghai, China, and used without further purification. The biomass used in this work was fir sawdust, a naturally abundant lignocellulosic biomass waste obtained from a local timber treatment plant in Hefei, China. After collected, the biomass was initially washed to remove impurity particles, and then dried in an oven at $378 \mathrm{~K}$ overnight. The dried biomass was crushed using a high-speed rotary cutting mill, and the biomass with the particle size smaller than 120 mesh were collected. The proximate analysis and elemental composition of the biomass were determined and the results were reported in our previous work ${ }^{24}$.

Synthesis of the magnetic porous carbonaceous solid acid catalyst. The precursor of solid acid catalyst was the Fe-loaded biomass, which was prepared in a biosorption process using biomass as an adsorbent at ambient temperature. Briefly, $10.0 \mathrm{~g}$ of biomass and $1,000 \mathrm{~mL}$ of $\mathrm{FeCl}_{3}$ solution with a concentration of $10 \mathrm{mmol} \mathrm{L}^{-1}$ were mixed in a flask and shaken in a constant temperature oscillator at $200 \mathrm{rpm}$ for $300 \mathrm{~min}$. Then, the water in the mixture was evaporated, and the solid residue was dried at $378 \mathrm{~K}$ overnight and sieved again to collect the particles with a size smaller than 120 mesh, and the Fe-loaded biomass with Fe content of approximately1.0 $\mathrm{mmol} \mathrm{g}^{-1}$ was obtained.

The magnetic porous carbonaceous solid acid catalyst was synthesized by fast pyrolysis of the Fe-loaded biomass and subsequent sulfonation of the produced biochar. The fast pyrolysis experiments were carried out in a vertical drop fixed bed reactor described in our previous work ${ }^{27}$. A 7.0 g portion of the Fe-loaded biomass sample was first placed in the feed pipe under a nitrogen flow of $400 \mathrm{~mL} \mathrm{~min}{ }^{-1}$, and the nitrogen flow was maintained for $20 \mathrm{~min}$ to remove air from the pyrolysis system. Subsequently, when the temperature rose to the setting value of $773 \mathrm{~K}$, the Fe-loaded biomass sample was inserted into the quartz tubular reactor with a piston for pyrolysis. The volatiles produced in the pyrolysis process were swept out by a nitrogen flow of $200 \mathrm{~mL} \mathrm{~min}{ }^{-1}$, and condensed by cold ethanol to obtain bio-oil. When the fast pyrolysis process was accomplished, the temperature of the heating zone was increased to $873 \mathrm{~K}$, and the bio-char was further carbonized for 1 hour. Finally, the reactor was moved out of the heating zone and cooled in the nitrogen flow to room temperature, and the magnetic porous carbonaceous material was obtained.

The solid acid catalyst was synthesized by sulfonation of the magnetic porous carbonaceous material. Briefly, the magnetic porous carbonaceous material was mixed with concentrated sulfuric acid (10 $\mathrm{mL}$ of sulfuric acid to 1 gram of solid), sonicated for $15 \mathrm{~min}$, and subsequently heated under vigorous stirring at $423 \mathrm{~K}$ for 10 hours to introduce sulfo-group $\left(\mathrm{SO}_{3} \mathrm{H}\right)$ on the surface of the materials. Afterwards, the mixture was cooled to room temperature, and then slowly added to a beaker containing 500-mL deionized water. The suspension mixture was then filtered off and washed repeatedly with deionized water until there was no sulfate ions $\left(\mathrm{SO}_{4}{ }^{2-}\right)$ detected in the washing (detected by $\mathrm{Ba}^{2+}$ solution). The solid was further washed with absolute ethanol to remove the water, and then dried at $353 \mathrm{~K}$ overnight. The dried sample was the magnetic porous carbonaceous solid acid and was stored for further use (MPC- $\left.\mathrm{SO}_{3} \mathrm{H}\right)$. For comparison, another carbonaceous solid acid was synthesized in the same way using raw biomass without $\mathrm{Fe}$-loading as precursor (PC$\left.\mathrm{SO}_{3} \mathrm{H}\right)$.

Characterization. The carbon (C) and sulfur (S) contents of the solid acids were analyzed using a high-frequency infrared carbon and sulfur analyzer (CS-600, LECO, USA), while the Fe content of the MPC-SO3H was determined by an X-ray fluorescence spectrometer (XRF-1800, Shimadzu Co., Japan). The total amount of acid sites was determined by an acid-base titration method using $\mathrm{NaOH}$ solution $\left(10 \mathrm{mmol} \mathrm{L}^{-1}\right)^{45}$

FTIR spectra were recorded on a Fourier transform infrared spectroscopy (Bruker EQUINOX55, Germany) to analyze the functional groups of the solid acid. The thermal stability of the solid acid was characterized with a DTG-60H/DSC-60 thermogravimetric analyzer (TGA, Shimadzu Co., Japan). The structural features of the solid acids were analyzed by nitrogen adsorption-desorption isotherms, performing at $77 \mathrm{~K}$ on a Micromeritics Gemini apparatus (ASAP $2020 \mathrm{M}+\mathrm{C}$, Micromeritics Co. USA) after degassing the sample at $393 \mathrm{~K}$ under vacuum for 10 hours. Specific surface areas of the solid acid were measured by tBET method, while their pore volumes were calculated by the amount of nitrogen adsorbed at a relative pressure of 0.99 . The surface morphology of the solid acid was analyzed using TEM (JEOL-2100F, Japan) and SEM (Sirion 200, FEI electron optics company, USA) coupled with EDX (INCA energy, UK). XPS measurements of the solid acid were performed using a Thermo VG-Scientific spectrometer (ESCALAB250, USA) with a monochromatized Al Ka radiation $(1486.92 \mathrm{eV})$. XRD analysis of the solid acids was carried out in an 18-KW rotating anode X-ray diffractometer (MXPAHF, Japanese Make Co., Japan).

Acid-catalyzed reactions. The catalytic activities of the solid acids were evaluated in three typical acid-catalyzed reactions, including esterification of benzylacohol and acetic acid (Reaction A), dehydration of the xylose to produce furfural (Reaction B), and hydrolysis of sucrose (Reaction C).

The esterification reaction was performed in a solvent-free system as follows: $0.100 \mathrm{~g}$ of catalyst was added to a $25 \mathrm{~mL}$ reaction tube, followed by the dose of $0.108 \mathrm{~g}$ $(1.0 \mathrm{mmol})$ of benzyl alcohol and $0.290 \mathrm{~g}(5.0 \mathrm{mmol})$ of acetic acid. Then, the mixture was vigorously stirred with a magnetic stirrer at $363 \mathrm{~K}$ to conduct the reaction. The reaction was completed in a nitrogen atmosphere and monitored by a thin layer chromatograph (TLC). After the reactions were accomplished (no benzyl alcohol was detected in the TLC), the reaction mixture was washed with cyclohexane of $10 \mathrm{~mL}$, and the catalyst was separated with the aid of a powerful magnet. The remaining cyclohexane solution was washed with $\mathrm{NaHCO}_{3}$ solution of $0.01 \mathrm{~mol} \mathrm{~L}^{-1}$ to remove the unreacted acetic acid, and then dried over anhydrous $\mathrm{MgSO}_{4}$. Finally, the products (benzyl acetate) was obtained after removal of the solvent under reduced pressure and confirmed by comparing the retention time with that of the pure benzyl acetate in a gas chromatograph. After reaction, the catalyst was separated by an external magnet, then washed with ethyl acetate several times, then dried at $333 \mathrm{~K}$ overnight and reused for subsequent reactions.

For the dehydration reaction, $\mathrm{d}-(+)-x y l o s e(0.150 \mathrm{~g}, 1 \mathrm{mmol})$, DMSO $(5.000 \mathrm{~g})$, and acid catalyst $(0.100 \mathrm{~g})$ were loaded into a $25-\mathrm{mL}$ reaction tube. The mixture was vigorously stirred and heated in a constant-temperature oil bath $(423 \mathrm{~K})$ for $300 \mathrm{~min}$. After reaction, the mixture was cooled to room temperature. The concentration of formed furfural was analyzed by gas chromatography, and the unreacted xylose content was determined by a phloroglucinol colorimetric assay using a UV-vis spectrophotometer (UV-1700, Phenix Optical Scientific Instrument Co., China ${ }^{46}$. The conversion of xylose and yield of furfural were calculated with Eqs. 6 and 7, respectively.

$$
\begin{gathered}
\text { Xylose yield }=\frac{\text { initial xylose }- \text { unreacted } x y l o s e}{\text { initial } x y l o s e} \\
\text { Furfural yield }=\frac{\text { furfural content }}{\text { initial xylose }} \times 100 \%
\end{gathered}
$$

For the hydrolysis reaction, sucrose $(0.342 \mathrm{~g}, 1 \mathrm{mmol})$, water $(20 \mathrm{~mL})$, and acid catalyst $(0.100 \mathrm{~g})$ were added into a $100-\mathrm{mL}$ round bottomed flask. The mixture was vigorously stirred and heated in a constant temperature oil bath $(353 \mathrm{~K})$ for $150 \mathrm{~min}$. After reaction, the mixture was cooled to room temperature. The hydrolysis products, i.e., glucose and fructose, were determined by a 3,5-dinitrosalicylic acid colorimetric assay on a UV-vis spectrophotometer (UV-1700, Phenix Optical Scientific Instrument Co., China) ${ }^{47}$. The unreacted sucrose was analyzed using the same method after hydrolysis in $6-\mathrm{mM} \mathrm{HCl}$ solution $(373 \mathrm{~K}$ ) for $5 \mathrm{~min}$. The conversion of sucrose and yields of hydrolysis products were calculated with Eqs. 8 and 9, respectively.

$$
\begin{aligned}
& \text { Sucrose conversion }=\frac{\text { initial sucrose }- \text { unreacted sucrose }}{\text { initial sucrose }} \times 100 \% \\
& \text { Hrdrolysis products yield }=\frac{\text { glucose and fructose content }}{\text { initial sucrose }} \times 100 \%
\end{aligned}
$$

1. Zhou, C.-H., Xia, X., Lin, C.-X., Tong, D.-S. \& Beltramini, J. Catalytic conversion of lignocellulosic biomass to fine chemicals and fuels. Chem. Soc. Rev. 40, 5588 (2011).

2. Hara, M. Biomass conversion by a solid acid catalyst. Energy Environ. Sci. 3, 601 (2010).

3. Taarning, E. et al. Zeolite-catalyzed biomass conversion to fuels and chemicals. Energy Environ. Sci. 4, 793 (2011).

4. Tanabe, K. \& Hölderich, W. F. Industrial application of solid acid-base catalysts. Appl. Catal. A. 181, 399 (1999).

5. Takagaki, A., Tagusagawa, C., Hayashi, S., Hara, M. \& Domen, K. Nanosheets as highly active solid acid catalysts for green chemical syntheses. Energy Environ. Sci. 3, 82 (2010).

6. Nakajima, K. \& Hara, M. Amorphous Carbon with SO3H Groups as a Solid Brønsted Acid Catalyst. ACS Catal. 2, 1296 (2012).

7. Xing, R. et al. Novel solid acid catalysts: Sulfonic acid group-functionalized mesostructured polymers. Adv. Func. Mater. 17, 2455 (2007).

8. Liu, F., Kong, W., Qi, C., Zhu, L. \& Xiao, F.-S. Design and synthesis of mesoporous polymer-based solid acid catalysts with excellent hydrophobicity and extraordinary catalytic activity. ACS Catal. 2, 565 (2012).

9. Akiyama, G., Matsuda, R., Sato, H., Takata, M. \& Kitagawa, S. Cellulose hydrolysis by a new porous coordination polymer decorated with sulfonic acid functional groups. Adv. Mater. 23, 3294 (2011).

10. Tagusagawa, C. et al. Highly active mesoporous $\mathrm{Nb}-\mathrm{W}$ oxide solid-acid catalyst. Angew. Chem. Int. Ed. 49, 1128 (2010).

11. Li, W. et al. Design of mesoporous $\mathrm{SO}_{4}{ }^{2-} / \mathrm{ZrO}_{2}-\mathrm{SiO}_{2}(\mathrm{Et})$ hybrid material as an efficient and reusable heterogeneous acid catalyst for biodiesel production. Green Chem. 12, 2135 (2010).

12. Gürbüz, E. I. et al. Conversion of hemicellulose into furfural using solid acid catalysts in $\gamma$-valerolactone. Angew. Chem. Int. Ed. 52, 1270-1274 (2012).

13. Hu, X., Lievens, C. \& Li, C.-Z. Acid-catalyzed conversion of xylose in methanolrich medium as part of biorefinery. ChemSusChem 5, 1427 (2012). 
14. Lange, J.-P., van de Graaf, W. D. \& Haan, R. J. Conversion of furfuryl alcohol into ethyl levulinate using solid acid catalysts. ChemSusChem 2, 437 (2009).

15. Wang, J. et al. Direct conversion of carbohydrates to 5-hydroxymethylfurfural using Sn-Mont catalyst. Green Chem. 14, 2506 (2012).

16. Shuai, L. \& Pan, X. Hydrolysis of cellulose by cellulase-mimetic solid catalyst. Energy Environ. Sci. 5, 6889 (2012).

17. Arancon, R. A., Barros, H. R. Jr., Balu, A. M., Vargas, C. \& Luque, R. Valorisation of corncob residues to functionalised porous carbonaceous materials for the simultaneous esterification/transesterification of waste oils. Green Chem. 13, 3162 (2011).

18. Wu, Y. et al. Microwave-assisted hydrolysis of crystalline cellulose catalyzed by biomass char sulfonic acids. Green Chem. 12, 696 (2010).

19. Gill, C. S., Price, B. A. \& Jones, C. W. Sulfonic acid-functionalized silica-coated magnetic nanoparticle catalysts. J. Catal. 251, 145 (2007).

20. Lai, D.-m., Deng, L., Guo, Q.-x. \& Fu, Y. Hydrolysis of biomass by magnetic solid acid. Energy Environ. Sci. 4, 3552 (2011).

21. Feyen, M., Weidenthaler, C., Schüth, F. \& Lu, A.-H. Synthesis of structurally stable colloidal composites as magnetically recyclable acid catalysts. Chem. Mater. 22, 2955 (2010).

22. Zillillah, Z., Tan, G. \& Li, Z. Highly active, stable, and recyclable magnetic nanosize solid acid catalysts: Efficient esterification of free fatty acid in grease to produce biodiesel. Green Chem. 14, 3077-3086 (2012).

23. Zafiropoulos, N. A., Ngo, H. L., Foglia, T. A., Samulski, E. T. \& Lin, W. Catalytic synthesis of biodiesel from high free fatty acid-containing feedstocks. Chem. Comm. 3670-3672 (2007).

24. Liu, W.-J. et al. Selectively Improving the Bio-oil quality by catalytic fast pyrolysis of heavy-metal-polluted biomass: Take copper $(\mathrm{Cu})$ as an example. Environ. Sci. Technol. 46, 7849 (2012).

25. Liu, W.-J., Zeng, F.-X., Jiang, H., Zhang, X.-S. \& Yu, H.-Q. Techno-economic evaluation of the integrated biosorption-pyrolysis technology for lead $(\mathrm{Pb})$ recovery from aqueous solution. Bioresour. Technol. 102, 6260 (2011).

26. Liu, W.-J., Zeng, F.-X., Jiang, H. \& Zhang, X.-S. Preparation of high adsorption capacity bio-chars from waste biomass. Bioresour. Technol. 102, 8247 (2011)

27. Liu, W.-J., Zeng, F.-X., Jiang, H. \& Yu, H.-Q. Total recovery of nitrogen and phosphorus from three wetland plants by fast pyrolysis technology. Bioresour. Technol. 102, 3471 (2011).

28. Mohan, D., Pittman, C. U. \& Steele, P. H. Pyrolysis of wood/biomass for bio-oil: A critical review. Energy Fuels 20, 848 (2006).

29. Czernik, S. \& Bridgwater, A. V. Overview of applications of biomass fast pyrolysis oil. Energy Fuels 18, 590 (2004)

30. Huber, G. W., Iborra, S. \& Corma, A. Synthesis of transportation fuels from biomass: Chemistry, catalysts, and engineering. Chem. Rev. 106, 4044 (2006).

31. Patwardhan, P. R., Brown, R. C. \& Shanks, B. H. Product distribution from the fast pyrolysis of hemicellulose. ChemSusChem 4, 636 (2011).

32. Gong, F. et al. Direct reduction of iron oxides based on steam reforming of bio-oil: a highly efficient approach for production of DRI from bio-oil and iron ores. Green Chem. 11, 2001 (2009).

33. Okamura, M. et al. Acid-catalyzed reactions on flexible polycyclic aromatic carbon in amorphous carbon. Chem. Mater. 18, 3039 (2006).

34. Tagusagawa, C. et al. Synthesis and characterization of mesoporous $\mathrm{Ta}-\mathrm{W}$ oxides as strong solid acid catalysts. Chem. Mater. 22, 3072 (2010).

35. Liu, Z. \& Zhang, F.-S. Nano-zerovalent iron contained porous carbons developed from waste biomass for the adsorption and dechlorination of PCBs. Bioresour. Technol. 101, 2562 (2010).

36. Maldonado-Hódar, F. J., Moreno-Castilla, C., Rivera-Utrilla, J., Hanzawa, Y. \& Yamada, Y. Catalytic graphitization of carbon aerogels by transition metals. Langmuir 16, 4367 (2000).
37. Atkinson, J. D. et al. Synthesis and characterization of iron-impregnated porous carbon spheres prepared by ultrasonic spray pyrolysis. Carbon 49, 587 (2011).

38. Lim, S.-F., Zheng, Y.-M., Zou, S.-W. \& Chen, J. P. Characterization of copper adsorption onto an alginate encapsulated magnetic sorbent by a combined FT-IR, XPS, and mathematical modeling study. Environ. Sci. Technol. 42, 2551 (2008).

39. Toupin, M. \& Belanger, D. Spontaneous functionalization of carbon black by reaction with 4-nitrophenyldiazonium cations. Langmuir 24, 1910 (2008).

40. Liu, F. et al. Sulfated graphene as an efficient solid catalyst for acid-catalyzed liquid reactions. J. Mater. Chem. 22, 5495 (2012).

41. Maciá-Agulló, J. A., Sevilla, M., Diez, M. A. \& Fuertes, A. B. Synthesis of carbonbased solid acid microspheres and their application to the production of biodiesel. ChemSusChem 3, 1352 (2010).

42. Li, X. et al. Sulfonated copolymers with $\mathrm{SO}_{3} \mathrm{H}$ and $\mathrm{COOH}$ groups for the hydrolysis of polysaccharides. J. Mater. Chem. 22, 1283 (2012).

43. Lam, E. et al. Synthesis of Furfural from Xylose by heterogeneous and reusable nafion catalysts. ChemSusChem 4, 535 (2011)

44. Agirrezabal-Telleria, I., Requies, J., Guemez, M. B. \& Arias, P. L. Furfural production from xylose + glucose feedings and simultaneous $\mathrm{N}_{2}$-stripping. Green Chem. 14, 3132-3140 (2012).

45. Jones, C. W., Tsuji, K. \& Davis, M. E. Organic-functionalized molecular sieves as shape-selective catalysts. Nature 393, 52 (1998).

46. Eberts, T., Sample, R., Glick, M. \& Ellis, G. A simplified, colorimetric micromethod for xylose in serum or urine, with phloroglucinol. Clin. Chem. 25, 1440-1443 (1979)

47. Tong, D. S. et al. Catalytic hydrolysis of cellulose to reducing sugar over acidactivated montmorillonite catalysts. Appl. Clay Sci. 74, 147-153 (2013).

\section{Acknowledgments}

The authors gratefully acknowledge financial support from National 863 Program (2012AA063608-01), National Key Technology R\&D Program of the Ministry of Science and Technology (2012BAJ08B00), and the Key Special Program on the S\&T for the Pollution Control and Treatment of Water Bodies (No.2012ZX07103-001).

\section{Author contributions}

W.J.L. designed and conducted the experiments, analyzed the data, and wrote the manuscript; H.J. provided guidance on the manuscript preparation, modified the manuscript, and supervised the whole work; K.T. conducted part of the experiments; H.Q.Y. modified this manuscript and provided important suggestions. All authors contributed through scientific discussions.

\section{Additional information}

Supplementary information accompanies this paper at http://www.nature.com/ scientificreports

Competing financial interests: The authors declare no competing financial interests.

How to cite this article: Liu, W.-J., Tian, K., Jiang, H. \& Yu, H.-Q. Facile synthesis of highly efficient and recyclable magnetic solid acid from biomass waste. Sci. Rep. 3, 2419; DOI:10.1038/srep02419 (2013).

This work is licensed under a Creative Commons Attribution-

NonCommercial-NoDerivs 3.0 Unported license. To view a copy of this license, visit http://creativecommons.org/licenses/by-nc-nd/3.0 